Intervención

\title{
Interpretaciones de un acontecimiento. Breve examen de la literatura sobre el octubre chileno
}

\author{
Luis Placencia* \\ *UNIVERSIDAD DE CHILE
}

\section{Presentación}

En la presente Intervención, el autor realiza un comentario detallado de tres libros sobre del acontecimiento político y social que significó el estallido social de octubre de 2019 en Chile de autoría de Carlos Peña, Hugo Herrera y Patricio Fernández. Se aborda el proceso de "modernización capitalista en Chile", como señala Peña, y el de la crisis de la derecha "neoliberal", como insiste Herrera, quien desde un punto de vista histórico argumenta la existencia de otras tradiciones (aunque desde un punto de vista político no haya mayor prueba de ello). Un comentario menor recibe el libro de Fernández, pero no porque haya que desmerecer su alcance: acaso su virtud, como enfatiza Placencia, es precisamente abstenerse de inscribir la rapsodia de sucesos dentro de un todo que los haga coherente, para permanecer en constatación inquieta y atenta de sus contradicciones.

\section{Introducción}

En este texto se discuten algunas de los aportes más relevantes a la discusión sobre el octubre chileno, intentando ponderar sus méritos, así como sus eventuales problemas. Lo anterior como resultado de la convicción del autor que la comprensión del así llamado "estallido social" requiere de un ejercicio de escucha y atención que no sólo debe pasar por auscultar las manifestaciones o las demandas populares en sus muy variadas formas sino también a los muy diferentes modos en que los acontecimientos de octubre y los meses posteriores han sido comprendidos por algunos autores que han acometido la tarea de comprenderlos. En esto, la literatura producida en estos meses provee un amplio crisol de fuentes que van desde los 
estudios de carácter sociológico, pasando por las reflexiones filosóficas sobre la naturaleza de la política o de los acontecimientos políticos, la crónica, el reportaje, las reflexiones históricas, etcétera. Se prestará especial atención a las obras de Patricio Fernández, Hugo Herrera, Pablo Oyarzún y Carlos Peña.

\section{Confesión}

Estamos lejos de comprender lo que pasó en octubre del 2019. Quien diga entenderlo del todo se tiene por más de lo que es. El acontecimiento fue una sorpresa, al menos para la mayoría. Cuando recuerdo el día clave, el día en que todo cambio de curso, no puedo evitar pensar que no sabíamos qué estaba pasando. No sé si ahora lo entendemos, pero hemos hecho esfuerzos. Este trabajo busca dar cuenta de algunos de ellos.

\section{Un recuerdo}

Volvamos por un momento al comienzo. Ello nos permitirá volver a mirar con calma el tipo de "objeto" que los trabajos en comento deben comprender. Al caer la noche del 18/10, los estudiantes del campus Juan Gómez Millas, el recinto universitario en el que trabajo, celebraban la "Fiesta de la Primavera". Los bailables retumbaban en parlantes instalados al aire libre, mientras centenares de jóvenes se agitaban al ritmo de las cumbias en un campus que se había tornado en pista de baile improvisada. El ambiente era distendido. No es poco común que los muchachos celebren en esas fechas. El clima invita a compartir en los espacios comunes universitarios y a disfrutar de la vida al aire libre. Además, ese día culminaba una semana de actividades organizadas por la Federación de Estudiantes de la Universidad de Chile, FECh, entre otras cosas, con el fin de ayudar a que los estudiantes enfrenten menos tensionados el semestre. Con todo, sí es llamativo que los mismos muchachos que estarían en las calles en los días subsecuentes y serían protagonistas del movimiento durante los meses venideros, hayan pasado esa noche bailando y festejando alegres. El 18/10 el campus, conocido por ser un lugar habitual de protestas y paros, danzaba en medio de la obscuridad nocturna al ritmo de las cumbias. 
Mientras eso ocurría, el tránsito ya estaba interrumpido en varias esquinas de la calle José Pedro Alessandri. Pensé al salir que varios de los alumnos que habían estado en seminario conmigo hasta las nueve de la noche iban a tener dificultades para retornar a sus casas. Los vecinos - muchos de los cuales padecen estoicamente los habituales cortes de calle en el sector- se agolpaban olla en mano en las esquinas, interceptaban ocasionalmente a los vehículos que circulaban y "caceroleaban" con rabia. Era "el estallido".

Como la mayoría, no caí en cuenta de la magnitud de lo que estaba ocurriendo sino con el paso de las horas. Al notar paulatinamente durante el sábado 19 de octubre que lo que se desataba era un fenómeno de proporciones cuyo origen no lograba comprender, me lancé a escribir. Intercambié además pareceres con amigos y conocidos. A partir de las conversaciones que tenía, me quedó rápidamente claro que no sabía qué pasaba ni por qué ocurría ni qué tendría lugar. Hice mis pronósticos. Poco importa cuáles eran. No se cumplieron. Mis expectativas, tampoco. Quedé desconcertado, por meses. Cuando recuerdo ese pasado (¿?) pienso que, en alguna medida, es un "hoy" que se ha extendido.

Ese "pasado" en el que muchos libros han intentado explicar, comprender, narrar. También se le ha intentado dar sentido, celebrarlo, execrarlo. Con algunos de esos esfuerzos vale la pena ocuparse. Pero no con todos. Hay una cierta condición que es valiosa, creo, para que tenga sentido el diálogo del lector con quien intenta entender lo que pasó.

\section{Sine ira et studio}

Los ánimos estaban ardiendo. Otro recuerdo me hace presente ese "estado": el Congreso de la Asociación Chilena de Filosofía tendría lugar en esos días en Pucón, Chile, del 21 al 25 de octubre. La organización decidió seguir adelante con el mismo, entre otras cosas, porque los invitados internacionales que ya estaban en Chile habían pedido que este tuviera lugar. La directiva explicó esto por medio de una declaración en la que además afirmó que "es nuestra convicción que las demandas pacíficas que se dejan oír hoy en nuestras calles son legítimas, y asimismo, que el liderazgo del actual gobierno refleja insensibilidad frente a ellas". Estas palabras, y la decisión de realizar el evento, trajeron consigo variadas reacciones de desaprobación. Algunos consideraron "frívolo" que el Congreso tuviera lugar en el contexto de conmoción que vivíamos. Otros consideraron inadecuada la mención a la "insensibilidad" 
del Gobierno, así como la omisión de la "violencia" de algunas manifestaciones en la declaración. Pocos llegamos a Pucón. Una vez ahí, como era de esperarse, conversamos sobre los sucesos de esos días. Algunos de los presentes, como Cristóbal Balbontín, leyeron interesantes reflexiones sobre la contingencia, mientras en la plaza de las afueras de la sede de la Universidad de la Frontera, un par de decenas de habitantes del pueblo se juntaban a protestar. En un improvisado panel discutimos sobre las circunstancias que se vivían: las violaciones a los derechos humanos, el estado de excepción, el lugar de la filosofía en la sociedad, entre otros. Uno de los organizadores, Ricardo Salas, propuso reunir las contribuciones ahí hechas, más otras que pudieran llegar, y compilarlas en un libro. El resultado fue Evadir. La filosofía piensa la revuelta de octubre 2019, editado por los mismos Balbontín y Salas, un texto que cuenta con 30 contribuciones de filósofos del medio nacional y que vio la luz en marzo de $2020^{1}$.

Los ejercicios de escritura y las conversaciones con amigos y colegas en Pucón me dejaron claro que no sólo casi todos estábamos convencidos de que los sucesos de octubre no eran de fácil comprensión, sino que además se requeriría mucha conversación y escucha para lograr una buena interpretación. Por ello me propuse inmediatamente la tarea de tratar de leer cuanto pudiera sobre lo que ocurría. Me propuse atender a los muchos aportes, que sabía vendrían, independiente de mi opinión previa sobre los autores o acerca de las ideas que ellos profesaban. La comprensión requiere tratar de aprehender lo que ocurre sine ira et studio. A continuación, intentaré de dar cuenta de las virtudes y problemas que me parece que presentan algunos de los textos que revisé, especialmente aquellos que fueron escritos con la misma disposición abierta a la conversación que traté de cultivar en mi lectura. Estimo, además, que los textos que discutiré satisfacen otra importante condición para lograr una genuina comprensión de los sucesos de octubre, a saber: presentar lo que podría considerarse como una doble perspectiva de ellos, en tanto nos presentan una explicación de los mismos así como un horizonte de sentido para ellos. En efecto, tanto o más importante que determinar qué causó lo que ocurrió en octubre es pensar qué haremos con ello. Se trata de dos preguntas diferentes, pero que un buen análisis de los hechos, al menos uno que aspire a cierta completud, debería acometer.

\footnotetext{
${ }^{1}$ Cristóbal Balbontín y Ricardo Salas eds. Evadir. La filosofía piensa la revuelta de octubre 2019 (Santiago: Libros del Amanecer editores, 2020).
} 


\section{Un punto de partida}

El sine ira et studio antes mentado parece ser fundamental. Mas no sólo ese acto de "desprendimiento" es necesario para un "diálogo" entre lector y autor que sea productivo. En su contribución al ya mencionado libro compilado por Balbontín y Salas, Pablo Oyarzún hace ver un aspecto clave, que debería ser -según me parece- el punto de entrada a cualquier intento de tematizar lo ocurrió en octubre. Dice Oyarzún:

Diversas voces han ofrecido sus hipótesis y diagnósticos. Algunas de ellas se han caracterizado por contar con interpretaciones generales, asentadas sobre premisas a las que ellas mismas conceden indiscutido crédito. Sin embargo, tengo la impresión de que esas son las que más lejos están de entender lo que ha pasado y sigue pasando. Hay un rasgo que, creo, las caracteriza a todas, que las caracteriza por más o por menos, pero es un rasgo común. Sea su combustible el malestar, la arrogancia o la euforia, coinciden en leer el acontecimiento con lo que ya saben. Dicho de otro modo, aplican al acontecimiento una plantilla conceptual previamente asegurada ${ }^{2}$.

Oyarzún llama la atención sobre el carácter de "acontecimiento" de lo ocurrido en octubre 3 . El uso que da a este término no busca dotar al mismo de significaciones teóricamente cargadas, sino que más bien apunta al sentido ordinario del mismo: un acontecimiento es algo que nos sorprende y que, como tal, puede situarse más allá del marco conceptual a partir del cual solemos comprender un hecho. Sobre este punto Oyarzún insiste en que una interpretación adecuada de los sucesos de octubre requiere de aceptar como punto de partida esta incapacidad de comprenderlo, reconocimiento que lleva a una apertura a lo que ocurre, y que permite "atender a lo que pasa". La atención a lo que ocurre en octubre nos debe llevar a captar que la fuerza de este acontecimiento es singularidad irreductible ${ }^{4}$.

\footnotetext{
${ }^{2}$ Pablo Oyarzún, "La fuerza de un acontecimiento", en Evadir. La filosofía piensa la revuelta de octubre 2019, C. Balbontín y R. Salas comps., 457.

${ }^{3}$ Ibid., 457.

${ }^{4}$ Ibid., 458-60.
} 
Una de las primeras contribuciones a las que tuve acceso recoge, en alguna medida, este punto. Se trata del libro de Hugo Herrera Octubre en Chile. Acontecimiento y comprensión política: hacia un republicanismo popular. Según Herrera, la situación que “expresa" la crisis de octubre tiene lugar a partir de una "crisis hermenéutica". Indica al comenzar el libro:

En los últimos años y por diversos factores, en los que es menester indagar, ha ido produciéndose una escisión entre la institucionalidad política y económica, los discursos y las obras políticas, de un lado, y, del otro, el pueblo y los anhelos y pulsiones suyos. Las dirigencias políticas, individual y colectivamente consideradas, no han estado a la altura de esa tarea hermenéutica básica. El resultado es que, en una medida importante, el pueblo ya no se siente reconocido en el sistema político, tampoco en el económico, y deviene rebelde ${ }^{5}$.

En rigor, el libro de Herrera no reconoce sus límites frente a lo que él mismo designa como "acontecimiento", que en el caso de su interpretación vendría a ser el "pueblo"6, sino más bien la incapacidad hermenéutica de las élites políticas de interpretar adecuadamente al pueblo. A ella le otorga el peso fundamental en los acontecimientos de octubre, que ve como continuos con una crisis previa, iniciada justamente por la pérdida de la capacidad de comprensión de la situación por parte de las élites ${ }^{7}$. La crisis desatada el 18/10 sería producto de un déficit de comprensión política que tendría como resultado la desconexión entre la institucionalidad política y económica, por un lado, y los "anhelos y pulsiones del pueblo". Ante la "interpelación" de este último, la primera habría sido incapaz de responder ${ }^{8}$. Lo anterior sería consecuencia de una mala comprensión de parte de la propia política de lo que sería su tarea: la de la "captación mediadora"9. Esta captación, sostiene Herrera, debe ser “intuitiva, reflexiva, prospectiva y creadora", es decir, debe sumergirse en la situación,

\footnotetext{
${ }^{5}$ Hugo Herrera, Octubre en Chile. Acontecimiento y comprensión politica: hacia un republicanismo popular (Santiago: Editorial Katankura, 2019), 14.

6 "[E]l pueblo no es una cosa, no un objeto determinable, sino, muchos más, acontecimiento"; "el pueblo no deja de ser (...) una fuerza que irrumpe desde honduras insondables y modos imprevisibles", ibíd., 16, 47.

${ }^{7}$ Ibíd., 40-2.

${ }^{8}$ Ibíd., 28.

${ }^{9}$ Ibid. 37.
} 
captarla, reflexionar sobre ella, conducirla y darle cauce institucional ${ }^{10}$. Contrario al ejercicio de la captación mediadora lograda del buen político, las élites que han conducido al Chile posterior a la Concertación han descansado en discursos "abstractos" 11, y de carácter "moralista" y "economicista"12. Con estos epítetos Herrera pretende recoger, por un lado, la posición de una izquierda que buscaría, según él, "ese estadio en que el individuo es purgado de su singularidad" 13 y que identifica con el Frente Amplio así como con las ideas de Fernando Atria; y por el otro, de una derecha que defendería una concepción atomista de la sociedad y la política ${ }^{14}$.

Herrera escribe su texto no sólo con el fin de diagnosticar lo ocurrido en octubre, sino también de proponer un camino. Este se identifica con lo que él llama "republicanismo popular". Los "principios" de este republicanismo son simples y económicos: "1) hay un sistema institucionalizado en el cual existe, además, división efectiva del poder social;2) el pueblo se siente reconocido en su institucionalidad"15.

La obra de Herrera, me parece, posee la gran virtud de detectar, en una época en que la política ha sido casi reducida a una especie de discusión de "políticas públicas", que la técnica no siempre propone los mejores caminos en las cuestiones públicas, así como de enfatizar que la razón de expertos, invocada con frecuencia entre nosotros, debe ser siempre ponderada junto con otros aspectos. Lo anterior ha sido puesto de relieve por quienes han destacado que en el origen de los hechos de octubre estuvo la decisión de un "panel de expertos" que determinaron -usando un algoritmo establecido por razones técnicas- un alza en el pasaje del transporte público ${ }^{16}$. Es claro que el texto de Herrera presenta una gran influencia de la tradición de la filosofía práctica, así como de la filosofía hermenéutica, dos vertientes que han sostenido un fructífero diálogo a partir de la década de los setenta del siglo pasado. Lo anterior se puede apreciar con bastante claridad a la luz del énfasis que pone Herrera en el carácter "artístico" de la política, en la medida en que ella debería operar

\footnotetext{
${ }^{10}$ Ibíd., 37-8.

${ }^{11}$ Ibid., 40.

12 Ibid., 44.

${ }^{13}$ Ibid., 85.

${ }^{14}$ Ibid., 68.

${ }^{15}$ Ibid., 104.

${ }^{16}$ Carlos Sanhueza, "No lo vimos venir. Los expertos bajo escrutinio", en Chile despertó. Lecturas desde la historia del estallido social de octubre, Mauricio Folchi ed. (Santiago: Facultad de Filosofía y Humanidades, Universidad de Chile, 2019) 43-51.
} 
siempre en el ámbito de la contingencia, entregada a la interpretación de situaciones específicas, y nunca aplicando reglas de modo mecánico ${ }^{17}$. Se trata, en alguna medida, de una advertencia que presta atención a la antigua observación aristotélica que hace ver que en el ámbito del obrar no se puede buscar la exactitud sino de un modo que sea propio al objeto ${ }^{18}$. Este trasfondo de la obra de Herrera rescata así, para bien según me parece, el carácter eminentemente práctico de la política.

Con todo, la idea puramente "artística" que tiene de la política parece no tener en cuenta de modo suficiente la relevancia de los mecanismos de mediación que suponen las reglas institucionales y que siempre están a la base de cualquier acto "intuitivo" del político. Estas mediaciones son también características de cualquier fenómeno práctico.

Para comprender lo anterior, es relevante tener en cuenta las observaciones que hace Herrera sobre el carácter orientador que juega para él la idea del juicio estético en Kant ${ }^{19}$. Si prestamos atención a la idea kantiana que sirve de símil para Herrera, hallaremos que hay múltiples diferencias de fondo con el juicio propio de un político. Ante todo, el juicio estético de gusto, que parece ser en lo que está pensando Herrera, supone, en el caso de Kant, una consideración desinteresada del objeto, lo cual quiere decir que ni siquiera interesa su existencia ${ }^{20}$. Además, en el caso del juicio de gusto hallamos un caso de enjuiciamiento del objeto en el que este "place sin concepto", lo cual quiere decir que el mismo es enjuiciado $\sin \operatorname{regla}^{21}$. Lo anterior parece decir algo respecto del escaso papel que parecen jugar las instituciones y las normas en la concepción de Herrera en el juicio político, casi como lugares vacíos que no deben tener contenido sustantivo alguno fijado de modo previo a la decisión popular. En este sentido, Herrera parece tener una concepción puramente "formal" de las instituciones y normas. En efecto, ellas pertenecerían al polo "formal" de la comprensión política, que debe articular lo que le es dado por el polo "real": "el pueblo en su territorio". El siguiente pasaje es revelador:

\footnotetext{
${ }^{17}$ Herrera, Octubre en Chile, 48.

${ }^{18}$ Ética Nicomaquea $1094 \mathrm{~b} 20$

${ }^{19}$ Herrera, Octubre en Chile, 18.

${ }^{20}$ Immanuel Kant, Gesammelte Schriften. Band V (Berlín: De Gruyter, 1968), 204-5.

${ }^{21}$ Ibid., 211.
} 
La comprensión se efectúa a partir de una actividad de articulación de la mente. Los productos de esa actividad de articulación, las palabras, las nociones, las ideas, las reglas, constituyen un polo ideal en la comprensión. La mente intuye o capta lo real, lo discierne y lleva la diversidad captada a la unidad de la consciencia. La mente es capaz de tomar distancia de la realidad, ganar altura, separarse de ella. En el pensar el sujeto recibe lo captado en la intuición y lo pone en palabras, en discursos, en obras, en instituciones ${ }^{22}$.

No se trata, por cierto, de que Herrera desconozca que las instituciones juegan un papel. Sin embargo, parece ser que ellas están entregadas a un plano que aparece casi exclusivamente condicionado por el plano "real". Dicho de otro modo: parece relevante que tengamos instituciones y que las respetemos, concede Herrera, pero no parece claro que ellas deban tener un contenido específico, que responda a alguna norma de racionalidad previa. De hecho, la referencia a reglas o instituciones que deben limitar los anhelos populares es casi total en el texto. En este sentido, el libro parece orientarse más por ideal "artístico" que por el de la racionalidad práctica en sentido estricto. En efecto, en el texto de Herrera parece pensarse la relación entre pueblo en su territorio, su hondura y las "formas", como una en la que "se pone" lo captado por el pensar, esto es, "lo real". Lo anterior parece olvidar que las naciones, e incluso la humanidad, podría decirse, no sólo poseen una historia que se documenta en el plano "real" -tal como lo llama Herrera- del "pueblo", sino que también lo hacen en sus instituciones, en sus palabras, en su lenguaje. No sólo el pueblo posee historia, sino también la racionalidad y sus formas. Ella debe proveer siempre límites a lo que la acción del político e incluso a lo que el pueblo en un determinado momento pueda "expresar". Dicho de otro modo: las instituciones y las normas no sólo deben proveer un "marco" formal de interpretación del "pueblo y su hondura" sino que deben ponerle límite. La discusión constitucional que tenemos ad-portas parece ser un buen momento para recordarlo.

\section{Causa y justificación}

${ }^{22}$ H. Herrera, Octubre en Chile, 49. 
En el punto anterior pone bastante énfasis el libro de Carlos Peña, Pensar el malestar. La crisis de octubre y la cuestión constitucional ${ }^{23}$. Se trata, como el título sugiere, de un texto que recoge explícitamente la cuestión de los sucesos de octubre en el contexto de la discusión constitucional a la que dieron lugar tales acontecimientos así como en el marco más amplio de la discusión sociológica sobre el problema del malestar que ya en la década de los noventa se suscitó a partir de los informes del Programa de las Naciones Unidas para el Desarrollo PNUD, y algunos trabajos de José Joaquín Brunner. La tesis general de Carlos Peña busca mostrar que la cuestión constitucional - a partir de la cual se intentó dar articulación política al malestar supuestamente revelado por el "estallido"- constituye una racionalización ex post que no coincide con las causas del mismo. Para ello resulta crucial distinguir entre "las razones justificatorias para una acción y las causas que la desatan" 24 . Contra muchas lecturas de acuerdo con las cuales las causas del "estallido social" radicarían en la desigualdad de la sociedad chilena, desigualdad que a su vez reclamaría para ser resuelta un cambio constitucional, Peña sugiere que las “causas" del estallido serían más bien propias del malestar generado por la modernidad, malestar que estaría motivado a su vez por una suma de factores como la "paradoja del bienestar" (el malestar surgido una vez que las mayorías acceden tras grandes esfuerzos a bienes largamente anhelados que antes eran distintivos y otorgaban un estatus que se pierde cuando se vuelven masivos) ${ }^{25}$, "el incremento de la vivencia de la desigualdad" (que es percibida como una desigualdad inmerecida); el cambio generacional (la anomia que sufriría la generación nacida en los 90) ${ }^{26}$, el cambio de clivaje de la política (la desaparición de la estructura de clases como elemento orientador de las preferencias políticas y el riesgo de populismo que conllevaría esta pérdida) ${ }^{27}$, el debilitamiento de los vínculos sociales ${ }^{28}$, y la obsolescencia de ciertas estructuras estatales (producto de su estructura decimonónica), ${ }^{29}$ que estarían a la base del estallido, y por ende

\footnotetext{
${ }^{23}$ Carlos Peña, Pensar el malestar. La crisis de octubre y la cuestión constitucional (Santiago: Editorial Taurus, 2020), 220.

${ }^{24}$ Ibid., 14.

${ }^{25}$ Ibid., 126.

${ }^{26}$ Ibid., 142.

${ }^{27}$ Ibid., 145.

${ }^{28}$ Ibíd., 148.

${ }^{29}$ Ibid., 149.
} 
no sería una mera cuestión de "un simple problema de justicia o una mera cuestión de diseño institucional"30.

Los factores antes mencionados no constituirían las únicas causas que se pueden dar del malestar, según destaca el mismo Peña, aunque sí serían elementos que cumplirían ese papel sin perjuicio de que se le pudieran añadir otros ${ }^{31}$. Con todo, el autor es enfático en descartar que lo que esté tras los sucesos de octubre sea una disputa de índole normativa en torno al modelo "neoliberal", al modo en que éste habría sido impugnado en libros como $\mathrm{El}$ otro modelo ${ }^{32}$.

Una vez establecido este diagnóstico, Peña aborda la cuestión constitucional. Más allá de que en el nivel de la explicación de las causas de los sucesos de octubre esta no tenga, según el autor, ninguna relevancia, él se manifiesta claramente favorable a tratarla como un modo adecuado de dar sentido a la crisis de octubre. Para ello, Peña trata una cuestión esencial aquí, a saber, la de la "legitimidad" constitucional. En este plano su análisis muestra que, aunque jurídicamente válida, la Constitución Política de 1980 ha perdido "legitimidad sociológica", las personas no parecen estar dispuestas a obedecer sus disposiciones con independencia del motivo ${ }^{33}$. Lo anterior abre paso a un análisis en que el autor se detiene en cuestiones relevantes para la decisión constitucional que, sin embargo, no parecen estar vinculadas con el problema de las causas de los fenómenos de octubre, aunque sí abren un horizonte de sentido para una posible resolución de las dificultades planteadas por los mismos. Peña aborda aquí las cuestiones de los derechos humanos como "coto vedado a la acción deliberada de los seres humanos" 34 , la cuestión de los derechos sociales ${ }^{35}$ y de la pluralidad cultural ${ }^{36}$, entre otras.

Uno de los aspectos positivos del libro de Peña es que la posibilidad de escribir más ampliamente parece darle también mayor capacidad de ser flexible en sus planteamientos, lo cual permite comprender mejor el alcance de sus tesis, la mayor parte de ellas bastante bien razonadas y equilibradas, a diferencia de la impresión que produjeron en muchos de sus

\footnotetext{
${ }^{30}$ Ibid., 152.

${ }^{31}$ Ibidem.

${ }^{32}$ Ibíd., 156-9. Ver también Fernando Atria, Guillermo Larraín, José Miguel Benavente, Javier Couso y Alfredo Joignant, El otro modelo: del orden neoliberal al régimen de lo público (Santiago, Editorial Debate, 2013).

${ }^{33}$ Ibid., 229-30.

${ }^{34}$ Ibid., 247.

${ }^{35}$ Ibid., 267-73.

${ }^{36}$ Ibid., 294-303.
} 
lectores varias de las columnas que publicó con ocasión del "estallido". Con todo, el libro parece tratar "el estallido" de una manera que reduce la búsqueda de causas al marco teórico dado por la sociología de la modernización y de los movimientos sociales, bajo el supuesto de que en ese contexto se hallaría la clave para comprender las causas de lo ocurrido. Este supuesto, con todo, parece operar sobre la base de la idea de que la crisis de octubre fue algo así como una expresión más de malestar que tiene lugar en las sociedades que han pasado por procesos de modernización capitalista. Sin embargo, dadas las advertencias relativas a la cuestión de la desigualdad -advertencias que el mismo Peña no desconoce-, cabe preguntarse si la modernización experimentada por el conjunto de la población posee un carácter tan uniforme que permite explicar los sucesos de octubre a partir de ese solo proceso que experimentaría la sociedad en su conjunto, y no ocurriría más bien que al menos una parte de ellos tendría su origen justamente en la acción de quienes poco o nada han formado parte de ese proceso, así como malamente han gozado de los beneficios de la "modernización". De ser esto así, cabría matizar al menos el diagnóstico de Peña ${ }^{37}$.

\section{Muchas miradas sobre ¿lo mismo?}

Comencé este texto haciendo ver que creía ver algo único en el caso del octubre chileno, algo que no se dejaba aprehender sin resto a partir de las categorías de las que disponemos. Los intentos de dar cuenta del fenómeno desde el punto de un punto de vista científico no pueden asumir esa premisa, pues justamente ello implicaría renunciar a su tarea. Con todo, octubre no sólo nos ha dado textos que intentan aprehender lo ahí ocurrido desde ese ángulo.

Un punto de partida mucho más cercano al que sugerí más arriba parece tener la obra de Patricio Fernández, Sobre la marcha. Notas acerca del estallido social en Chile. Este texto no es, a diferencia de los libros de Herrera y Peña, un escrito con pretensiones filosóficas, sociológicas o académicas, sino más bien algo más cercano a un reportaje. Como tal, parece

\footnotetext{
${ }^{37}$ No es necesario para ello suscribir diagnósticos como el ofrecido por Alberto Mayol en El derrumbe del modelo. La crisis de la economía de mercado en el Chile contemporáneo (Santiago: Lom ediciones, 2012), o el mencionado El otro modelo. Recientemente, por ejemplo, Felipe Schwember ha intentado una explicación alternativa del fenómeno denominado como "la violencia", que no la comprende como generada por un mero “malestar” propio de la modernidad. Ver Felipe Schwember, “¿El eterno retorno de la violencia? Las injusticias históricas y el estallido de octubre", en El octubre chileno. Reflexiones sobre democracia y libertad, B. Ugalde, F. Schwember y V. Verbal eds. (Santiago: Editorial Democracia y Libertad, 2020), 109-34.
} 
abrirse de modo particularmente flexible a la narración de lo ocurrido. No se trata, con todo, de un texto que pretenda describir los sucesos de modo "neutral" u "objetivo". Nos presenta más bien la perspectiva de un observador comprometido y situado "en medio de los acontecimientos que relata" 38 . Esta mirada además es presentada en la forma de notas, que son cada vez más fragmentarias a medida que se avanza en el libro, como si el autor quisiera transmitir al lector su desconcierto, unido a la vez a su fascinación ${ }^{39}$. El texto parece construir así una especie de "mosaico" que a la larga constituye un todo de partes muy diferentes. Ese todo es el de un observador que cierra el texto con un cartel que reza "confianza en la gente para escribir la constitución del pueblo" ${ }^{40}$. Las partes del mosaico son algunos de los muchos que se manifestaron y que muchas veces aparecen retratados en sus propias palabras o expresiones: el mundo feminista, los estudiantes secundarios, los universitarios, los indignados, los “amarillos", los barreros, los mapuche, los habitantes de la marginalidad, los que pasaron por el Servicio Nacional de Menores, entre otros. Abundan en este contexto las descripciones de grafitis y diversas formas de arte callejero. El carácter de "apuntes de un observador" que presenta el libro, uno que por lo demás no hesita en presentar su perplejidad frente a la deriva de los hechos, es particularmente útil para "observar" octubre a la distancia.

Abundan referencias que permiten hacerse una idea de eventuales "causas" del estallido, así como es clara una perspectiva que permite darle un horizonte de solución. Son frecuentes las alusiones al carácter completamente desorientado del gobierno y buena parte de la clase política ante los sucesos de octubre. Al igual que en el caso del libro de Herrera, la cuestión de la desconexión entre las élites políticas y el pueblo aparece como central. Fernández, con todo, agrega un elemento que no parece ser menor y que el texto de Herrera no presenta: no sólo las élites políticas son parte de esa desconexión, sino de todos quienes son llamados como "los dueños del poder" ${ }^{41}$. Ellos se habrían resistido a comprender que

\footnotetext{
${ }^{38}$ Patricio Fernández, Sobre la marcha. Notas acerca del estallido social en Chile (Santiago: Editorial Debate, 2020), 13.

39 “Ante los hechos que vivimos, constato que toda conclusión, toda explicación, empobrece. El relato, en cambio, se multiplica infinitamente", ibid., 49.

${ }^{40}$ Ibid., 183.

${ }^{41}$ Ibid., 78. Una desconexión similar entre élites y pueblo es presentada como origen del estallido en la crónica de Óscar Contardo Antes de que fuera octubre. El texto parece partir de un punto de partida diferente a los anteriormente mencionados. Se trata de reconocer, a través de la narración de determinados hitos del Chile de la postdictadura que en rigor el estallido no fue "tan repentino" ni tan "poco predecible" como algunos parecieron sugerir. Ver Óscar Contardo, Antes de que fuera octubre (Santiago: Editorial Planeta, 2020), 4. Junto con ello, se vuelve a presentar la desconexión entre los diagnósticos de al menos una parte de las élites intelectuales y los signos de "insatisfacción” de las mayorías.
} 
Chile es más diverso que el mundo que habita en sus mentes, lo cual termina sometiéndolos a la pobreza intelectual.

La lectura del libro de Fernández nos muestra que éste tiene un mérito que, aunque no puede ser la gracia de un libro "académico", nos devuelve al punto de partida que es quizás en el que estaremos un buen tiempo: octubre parece haber sido muchos. Quizás podremos explicarlos plausiblemente desde muchos ángulos, pero no lograremos darle un sentido -si acaso puede llegar a tenerlo- mientras no logremos reconducir esa multiplicidad a una experiencia que haya sido nuestra.

\section{Libros reseñados}

Fernández, Patricio. Sobre la marcha. Notas acerca del estallido social en Chile. Santiago: Editorial Debate, 2020. 184 pp. ISBN 9789566042235.

Herrera, Hugo. Octubre en Chile. Acontecimiento y comprensión política: hacia un republicanismo popular. Santiago de Chile: Editorial Katankura, 2019. 141 pp. ISBN 9789560942012.

Peña, Carlos. Pensar el malestar. La crisis de octubre y la cuestión constitucional. Santiago: Editorial Taurus, 2020. 340 pp. ISBN 9789569635403. 


\section{Referencias bibliográficas}

Balbontín, Cristóbal y Ricardo Salas editores. Evadir. La filosofía piensa la revuelta de octubre 2019. Santiago: Libros del Amanecer editores, 2020.

Contardo, Óscar. Antes de que fuera octubre. Santiago: Editorial Planeta, 2020.

Kant, Immanuel. Gesammelte Schriften. Band V. Berlín: De Gruyter, 1968.

Oyarzún, Pablo. "La fuerza de un acontecimiento". En Evadir. La filosofía piensa la revuelta de octubre 2019, Cristóbal Balbontín y Ricardo Salas editores, 457-62. Santiago: Libros del Amanecer editores, 2020.

Sanhueza, Carlos. "No lo vimos venir. Los expertos bajo escrutinio". En Chile despertó. Lecturas desde la historia del estallido social de octubre, Mauricio Folchi editor, 4351. Santiago: Facultad de Filosofía y Humanidades de la Universidad de Chile, 2019. Schwember, Felipe. “¿El eterno retorno de la violencia? Las injusticias históricas y el estallido de octubre”. En El octubre chileno. Reflexiones sobre democracia y libertad, Benjamín Ugalde, Felipe Schwember y Valentina Verbal editores. Santiago: Editorial Democracia y Libertad, 2020.

\section{Sobre el autor}

Luis Placencia. Profesor Asociado de la Facultad de Filosofía y Humanidades, Departamento de Filosofía de la Universidad de Chile (Santiago, Chile). Profesor Asistente de la Facultad de Derecho, Departamento de Ciencias del Derecho de la Universidad de Chile. Doctor en Filosofía por la Martin-Luther-Universität Halle-Wittenberg. Correo electrónico: luis.placencia@uchile.cl. 